\title{
Performance evaluation of happy seeder for sowing wheat crop in combined harvested
}

\section{PRASHANT SINGH, BALVINDRA SINGH GAUTAM AND RAHUL KUMAR YADAV}

Received : 07.08.2017; Revised : 12.09.2017; Accepted : 28.09.2017

See end of the Paper for authors' affiliation

Correspondence to :

PRASHANT SINGH

Department of Farm Machinery and Power Engineering, Vaugh School of Agricultural Engineering and Technology, Sam Higginbottom Institute of Agriculture, Technology and Science, ALLAHABAD (U.P.) INDIA
- ABSTRACT : The present study was undertaken on happy seeder for wheat crop under ricewheat the cropping system in Allahabad region. In this study evaluate the performance of the happy seeder with conventional method and show its effectiveness over the sowing technique. The performance evaluation was done from the basis of field capacity, field efficiency, actual field capacity, fuel consumption and cost of operation, the compression of economics of operation of happy seeder with conventional method of sowing wheat in combined harvested paddy field, to prove the effectiveness. The operating speed was varying from 2.5 to $3.5 \mathrm{kmph}$ to evaluate the variables. The field efficiency of happy seeder was $43.4 \%$ and $65.04 \%$ for seed drill at operating speed of $3.5 \mathrm{kmph}$. The crop residue is heavy which was collected by sampling. The cost of operating per hectare by happy seeder was Rs. 2098.65 and cost of operation per hectare by seed drill + tillage operations was Rs. 3106.38. Therefore cost of operational with happy economical as compared to seed drill by Rs. 1008.38 per hectare. But happy seeder is unique technique for sowing wheat in combine harvested paddy field. It controls the weeds also.

- KEY WORDS : Happy seeder, Rice, Wheat, Seed drill

- HOW TO CITE THIS PAPER : Singh, Prashant, Gautam, Balvindra Singh and Yadav, Rahul Kumar (2017). Performance evaluation of happy seeder for sowing wheat crop in combined harvested. Internat. J. Agric. Engg., 10(2) : 643-646, DOI: 10.15740/HAS/IJAE/10.2/643-646. 